\title{
Dynamic light absorption of biomass-burning organic carbon photochemically aged under natural sunlight
}

\author{
M. Zhong and M. Jang \\ Correspondence to: M. Jang (mjang@uff.edu) \\ Received: 18 June 2013 - Published in Atmos. Chem. Phys. Discuss.: 9 August 2013 \\ Revised: 2 December 2013 - Accepted: 5 January 2014 - Published: 11 February 2014
}

Department of Environmental Engineering Sciences, P.O. Box 116450, University of Florida, Gainesville, FL 32611, USA

\begin{abstract}
Wood-burning aerosol produced under smoldering conditions was photochemically aged with different relative humidity $(\mathrm{RH})$ and $\mathrm{NO}_{\mathrm{x}}$ conditions using a $104 \mathrm{~m}^{3}$ dual outdoor chamber under natural sunlight. Light absorption of organic carbon (OC) was measured over the course of photooxidation using a UV-visible spectrometer connected to an integrating sphere. At high $\mathrm{RH}$, the color decayed rapidly. $\mathrm{NO}_{\mathrm{x}}$ slightly prolonged the color of wood smoke, suggesting that $\mathrm{NO}_{\mathrm{x}}$ promotes the formation of chromophores via secondary processes. Overall, the mass absorption cross section (integrated between 280 and $600 \mathrm{~nm}$ ) of OC increased by $11-54 \%$ (except high RH) in the morning and then gradually decreased by $19-68 \%$ in the afternoon. This dynamic change in light absorption of wood-burning OC can be explained by two mechanisms: chromophore formation and sunlight bleaching. To investigate the effect of chemical transformation on light absorption, wood smoke particles were characterized using various spectrometers. The intensity of fluorescence, which is mainly related to polycyclic aromatic hydrocarbons (PAHs), rapidly decreased with time, indicating the potential bleaching of PAHs. A decline of levoglucosan concentrations evinced the change of primary organic aerosol with time. The aerosol water content measured by Fourier transform infrared spectroscopy showed that woodburning aerosol became less hygroscopic as photooxidation proceeded. A similar trend in light absorption changes has been observed in ambient smoke aerosol originating from the 2012 County Line wildfire in Florida. We conclude that the biomass-burning OC becomes less light absorbing after 8$9 \mathrm{~h}$ sunlight exposure compared to fresh wood-burning OC.
\end{abstract}

\section{Introduction}

Atmospheric aerosols that can both absorb and scatter sunlight remain the largest source of uncertainty in radiative forcing of climate (Forster et al., 2007). Among various atmospheric aerosols, only carbonaceous aerosol and some mineral dusts have the potential to cause climate-warming by directly absorbing solar radiation (Bond and Bergstrom, 2006; Gu et al., 2012). Carbonaceous aerosol includes both organic carbon (OC) and black carbon (BC) aerosol. In this study, $\mathrm{BC}$ and elemental carbon (EC) are treated as equivalent (Bahner et al., 2007). BC is well known for its climatewarming effect (Bond et al., 2013; Quinn et al., 2008; Jacobson, 2000). Light absorption of OC has been poorly understood mainly due to its complex chemical composition and dynamic evolution under atmospheric conditions (Jimenez et al., 2009; Rudich et al., 2007). OC can be either primary (POA) or secondary (SOA) in origin. On a global scale, approximately $69 \%$ of POA and $23 \%$ of SOA are contributed by biomass burning (Hallquist et al., 2009). Considering the large source of biomass-burning OC in the atmosphere, better understanding its light absorption properties is necessary.

Recently, there has been growing evidence that biomassburning OC may be a nonnegligible contributor to light absorption in atmospheric aerosols, especially in the shortwavelength visible and ultraviolet spectral regions (Hoffer et al., 2006; Kirchstetter and Thatcher, 2012; Lack et al., 2012). Kirchstetter and Thatcher (2012) analyzed the filterbased wood smoke aerosol from nighttime ambient sampling and estimated that OC accounted for $49 \%$ of total aerosol light absorption between 300 and $400 \mathrm{~nm}$. Lack et al. (2012) measured light absorption of biomass-burning aerosol originating from a wildfire event using a photo-acoustic aerosol 
absorption spectrometer. Their results suggested that the primary biomass-burning OC contributed $27( \pm 15) \%$ of the total absorption at $404 \mathrm{~nm}$.

Light absorption of OC is mainly determined by its chemical composition. Biomass-burning OC has a yellowish to brown color, with absorption mainly in the UV range and decreasing absorption toward visible range (Kirchstetter et al., 2004; Schnaiter et al., 2005). Chen and Bond (2010) measured light absorption of solvent-extracted fresh primary OC generated in a nitrogen-filled furnace. They proposed that chemicals with large, polar, and conjugated aromatic rings would be the light-absorbing materials. The study of Del Vecchio and Blough (2004) suggested that hydroxyaromatic compounds and quinoid might be responsible for OC color.

In the atmosphere, the chemical composition of OC aerosol changes with aging through processes such as oxidation of organic gases, heterogeneous oxidation with atmospheric oxidants (e.g., ozone and $\mathrm{OH}$ radicals), and aerosolphase reactions. Recent laboratory experiments indicate that photochemical oxidation results in the dynamic evolution of chemical and physical properties of OC. The aged OC aerosol became less volatile and more oxygenated after a few hours of photochemical oxidation (Grieshop et al., 2009). Aging processes also change the hygroscopicity. The hygroscopic water content in OC aerosol may increase or decrease depending on wood-burning conditions (Martin et al., 2013).

Due to the different aging times and oxidation conditions, the aging effects on the light-absorbing properties of OC have varied among research reports. For example, Adler et al. (2011) derived the effective broadband refractive index of biomass-burning aerosol from a wood-burning event using a white-light optical counter. They found that the aged biomass-burning aerosols were less absorptive than the freshly emitted aerosols, with the imaginary refractive index decreasing from 0.04 to 0.02. However, Saleh et al. (2013) recently reported that aged $\mathrm{OC}$ is more absorptive than fresh OC due to SOA formation. In their study, the wood smoke aerosol was aged only for $1 \mathrm{~h}$ using an indoor chamber. These conflicting results show that the influence of aging on light absorption of wood smoke OC needs further investigation.

The objectives of this study are (1) to investigate the influence of photochemical oxidation on light absorption of wood smoke OC, (2) to explore the effects of relative humidity (RH) and $\mathrm{NO}_{\mathrm{x}}$ on light absorption of wood smoke OC over the course of the photochemical aging process, and (3) to characterize the chemical evolution of OC aerosol. In order to focus on wood-burning $\mathrm{OC}$ with minimal influence by $\mathrm{BC}$, wood smoke was produced via smolderingphase burning. The smoldering phase is characterized by a flameless form of combustion, producing low fractions of black carbon ( $2-5 \%$ by mass) in the aerosol phase (Reid et al., 2005). Smoldering combustion has frequently been found in biomass-burning situations including wildfires, prescribed burns, and agriculture burning (Alves et al., 2011;
Hille and Stephens, 2005; Hays et al., 2005). Smolderingphase burning has been reported to consume over $50 \%$ of biomass in temperate and boreal fires (Bertschi et al., 2003). In this study, wood-burning OC emissions were photochemically oxidized using a large outdoor chamber $\left(104 \mathrm{~m}^{3}\right)$. Natural sunlight was used as the radiation source. The large outdoor chamber allowed for atmospheric aging conditions to be closely mimicked and aerosol samples to be collected for longer time periods.

\section{Methods}

\subsection{Outdoor chamber experimental setup}

The photooxidation of wood smoke was performed using the University of Florida Atmospheric Photochemical Outdoor Reactor (UF-APHOR) dual chambers $\left(52 \mathrm{~m}^{3}\right.$ per chamber), which are located on the roof of Black Hall, University of Florida. The UF-APHOR dual chambers with half-cylinder design are made of FEP Teflon film attached to metal frames. A detailed description of the UF-APHOR chambers can be found elsewhere (Im et al., 2013).

Prior to each experiment, the chambers were continuously flushed with clean ambient air for more than $12 \mathrm{~h}$ and then purged overnight with clean air from an air cleaner (GC Series, IQAir Inc.). Commercial hickory hardwood logs were chopped into pieces with an approximate size of $3 \mathrm{~cm} \times 4 \mathrm{~cm} \times 33 \mathrm{~cm}$. The wood pieces were burned under smoldering conditions using a wood grill stove. Before sunrise, smoke was introduced into the chambers through an alumina tube ( 4 in. diameter, $1.6 \mathrm{ft}$ length) connected to the stove. Immediately after injecting wood smoke, the chamber air was mixed for 5 min using mixing fans. The initial conditions for wood smoke particle concentration measured by an organic carbon (OC) analyzer are summarized in Table 1. For high- $\mathrm{NO}_{\mathrm{x}}$ experiments, $\mathrm{NO}$ gas from the tank was introduced into the chamber after the wood smoke injection.

Photochemical reactions started at sunrise. The sunlight intensity, chamber temperature, and chamber relative humidity $(\mathrm{RH})$ dynamically changed over the course of chamber experiments. A typical time profile of these parameters is shown in Fig. S1. To study the effect of humidity on photochemical aging of wood smoke, the dry condition humidity $(\mathrm{RH}<30 \%)$ was controlled one day prior to the experiment using a dehumidifier. To achieve the wet condition $(\mathrm{RH}>60 \%)$, the chamber air was humidified using a steam evaporator during the experiment. Sunlight intensity and chamber temperature as well as chamber humidity were measured continuously with an ultraviolet radiometer (model TUVR, the Eppley Laboratory) and a Temp-RH sensor (CS2, Campbell Scientific), respectively. 
Table 1. Summary of experimental conditions of fresh wood smoke before photochemical oxidation.

\begin{tabular}{llccccccl}
\hline No. & Date & Chamber & $\begin{array}{c}\mathrm{RH} \\
\%\end{array}$ & $\begin{array}{c}\text { Temp, } \\
\mathrm{K}\end{array}$ & $\begin{array}{c}\text { Initial } \\
\mathrm{NO}_{\mathrm{x}}, \mathrm{ppb}\end{array}$ & $\begin{array}{c}\text { Initial } \\
\mathrm{OC}, \mu \mathrm{g} \mathrm{m}^{-3}\end{array}$ & $\begin{array}{c}\mathrm{EC} / \mathrm{TC}, \\
\%\end{array}$ & Notes \\
\hline 1 & 11 Oct 2012 & $\mathrm{E}$ & $39-95$ & $291-312$ & 43 & 56 & 4.7 & medium $\mathrm{NO}_{\mathrm{x}}$ \\
2 & 11 Oct 2012 & $\mathrm{W}$ & $51-95$ & $291-311$ & 16 & 40 & 5.5 & low $\mathrm{NO}_{\mathrm{x}}$ \\
3 & 30 Oct 2012 & $\mathrm{E}$ & $21-87$ & $275-300$ & 108 & 58 & 4.1 & ${\text { high } \mathrm{NO}_{\mathrm{x}}}$ \\
4 & 30 Oct 2012 & $\mathrm{W}$ & $26-88$ & $275-297$ & 16 & 68 & 3.3 & low $\mathrm{NO}_{\mathrm{x}}$ \\
5 & 24 Oct 2012 & $\mathrm{E}$ & $10-26$ & $291-311$ & 5 & 58 & 3.2 & low RH \\
6 & 24 Oct 2012 & $\mathrm{W}$ & $80-87$ & $291-310$ & 6 & 58 & 3.6 & high RH \\
7 & 01 Nov 2012 & $\mathrm{E}$ & $12-23$ & $281-306$ & 5 & 111 & 4.3 & low RH \\
8 & 01 Nov 2012 & $\mathrm{W}$ & $56-75$ & $283-304$ & 6 & 77 & 2.8 & medium RH \\
9 & 21 Nov 2012 & $\mathrm{E}$ & $67-87$ & $285-305$ & 10 & 144 & 2.5 & chemical analysis \\
\hline
\end{tabular}

\subsection{Wood smoke characterization}

Gas and particles were sampled through manifolds that run directly to a laboratory just below the chambers. The wood smoke particles were collected on a $13 \mathrm{~mm}$ diameter filter (Borosilicate microfibers reinforced with woven glass cloth and bonded with Teflon, Gelman Science Pallflex, type TX40H120-WW) at a flow rate of $17 \mathrm{~L} \mathrm{~min}^{-1}$. The UVvisible light absorption spectrum of aerosols collected on the filter was directly monitored using a Perkin-Elmer Lambda 35 UV-visible spectrophotometer equipped with a Labsphere RSA-PE-20 diffuse reflectance accessory. The detailed measurement procedure for light absorption spectra of aerosols can be found in our previous study (Zhong and Jang, 2011). $\mathrm{OC}$ and elemental carbon (EC) of the aerosol filter samples were analyzed with a semicontinuous OC/EC analyzer (model 4, Sunset Laboratory Inc.). Levoglucosan obtained from the filter-acetonitrile extract was first derivatized with N,O-bis(trimethylsilyl) trifluoroacetamide(BSTFA) and then measured using a gas chromatograph-ion trap mass spectrometer (GC-ITMS) (CP-3800 GC, Saturn 2200 MS, Varian Inc.). The fluorescence spectra of extract of the filter sample with dichloromethane were measured by a fluorescence spectrophotometer (F-2500, Hitachi Ltd.). The chemical functional group of particles impacted on a silicon disk was characterized using Fourier transform infrared spectroscopy (FTIR) (Nicolet Magna 560, SpectraLab Scientific Inc). To determine the water content of aerosols, the sampled silicon disk was installed in a miniature flow chamber that was located in the FTIR optical beam path. The relative humidity inside the flow chamber was controlled by passing wet air through the chamber. FTIR spectra of aerosols on the disk were obtained under varying relative humidity from 10 to $85 \%$. Detailed descriptions of the methods can be found in the previous study by Jang et al. (2010). Particle concentrations and particle size distributions were monitored continuously using a scanning mobility particle sizer (model 3080, TSI Inc.) together with a condensation nuclei counter (model 3025A, TSI Inc.). Ozone was monitored using a photometric ozone analyzer (model 400E, Teledyne
Instruments), and $\mathrm{NO}_{\mathrm{x}}$ concentrations were measured using a chemiluminescence $\mathrm{NO} / \mathrm{NO}_{\mathrm{x}}$ analyzer (model $200 \mathrm{E}$, Teledyne Instruments).

\subsection{Light absorption of ambient aerosol}

In April 2012, the County Line fire that occurred in Pinhook Swamp, Florida, 90 miles north of UF, burned more than 10000 acres. Biomass-burning aerosol was collected at the UF sampling site on 9-10 April 2012. During the sampling day, the $\mathrm{OC}$ concentration in the morning was as high as $92 \mu \mathrm{g} \mathrm{m}^{-3}$ (measured at the sampling site); an OC value on a normal day is 2 to $4 \mu \mathrm{g} \mathrm{m}^{-3}$. Thus, wildfire emission was the main source of the ambient aerosols in UF area during this episode. Fine particulate matter $\left(\mathrm{PM}_{2.5}\right)$ passing through a cyclone was collected on a $13 \mathrm{~mm}$ diameter filter at a flow rate of $16.7 \mathrm{~L} \mathrm{~min}^{-1}$. Light absorption spectra of the filter sample were directly measured using a UV-visible spectrometer equipped with an integrating sphere.

\section{Results and discussion}

\subsection{Light absorption of OC}

Due to the strong light absorption capacity, a small amount of BC may contribute significant spectral absorption depending upon wavelength. Hence, burning conditions were maintained as smoldering to generate less BC. The percentage of EC in smoldering smoke particles was near or less than 5\%, as shown in Table 1. A method introduced by Kirchstetter and Thatcher (2012) was used to separate light absorption by $\mathrm{OC}$ from the absorption of the smoke aerosol mixture (OC and $\mathrm{BC}$ ). Light absorption of $\mathrm{OC}, \mathrm{Abs}_{\mathrm{OC}}$, is obtained by subtracting the absorption of $\mathrm{BC}, \mathrm{Abs}_{\mathrm{BC}}$, from the mixture's absorption Abs:

$\mathrm{Abs}_{\mathrm{OC}}=\mathrm{Abs}-\mathrm{Abs}_{\mathrm{BC}}$. 
Abs is directly measured from the filter sample. Abs $_{B C}$ is estimated as

$\mathrm{Abs}_{\mathrm{BC}}=\frac{\operatorname{Abs}(880 \mathrm{~nm})}{880 \mathrm{~nm}^{-\mathrm{AAE}}} \lambda^{-\mathrm{AAE}}$,

where AAE is the absorption Ångström exponent, defined as

$\mathrm{AAE}=\frac{-\ln \left(\operatorname{Abs}_{\mathrm{BC}}\left(\lambda_{1}\right) / \operatorname{Abs}_{\mathrm{BC}}\left(\lambda_{2}\right)\right)}{\ln \left(\lambda_{1} / \lambda_{2}\right)}$.

For $\mathrm{Abs}_{\mathrm{BC}}$ estimation, the measured $\mathrm{AAE}$ value was 1.03 for wavelengths between 360 and $900 \mathrm{~nm}$.

Figure 1a shows absorption spectra of the fresh smoke aerosol, the decoupled OC, and the decoupled BC. Over the wavelength range between 280 and $600 \mathrm{~nm}$, OC contributes $60-98 \%$ of the total sample absorption, while BC is dominate for longer wavelengths $(>700 \mathrm{~nm})$. Light absorption of OC exhibits no distinct peaks, exponentially decreasing with increasing wavelength. In the visible range $(400-700 \mathrm{~nm})$, the average AAE of $\mathrm{OC}$ is 4.74. This value accords with the AAE of ambient biomass-burning OC (an average value of 5) reported by Kirchstetter and Thatcher (2012).

All samples were analyzed in a similar manner as described above. The main data reported here are mass absorption cross section of OC $\left(\mathrm{MAC}_{\mathrm{OC}}, \mathrm{m}^{2} \mathrm{~g}^{-1}\right)$, which is wavelength $(\lambda)$ dependent and determined by normalizing the absorption coefficient of $\mathrm{OC}\left(b_{\mathrm{abs}(\mathrm{OC})}, \mathrm{m}^{-1}\right)$ with thermal OC mass concentration, $M_{\mathrm{OC}}\left(\mathrm{g} \mathrm{m}^{-3}\right.$, measured by an $\mathrm{OC} / \mathrm{EC}$ analyzer):

$\mathrm{MAC}_{\mathrm{OC}}=\frac{b_{\mathrm{abs}(\mathrm{OC})}}{M_{\mathrm{OC}}}$.

In Eq. (4), $b_{\mathrm{abs}(\mathrm{OC})}$ can be calculated from AbsoC:

$b_{\mathrm{abs}(\mathrm{OC})}=\frac{1}{f} \frac{A}{V} \mathrm{Abs}_{\mathrm{OC}} \ln (10)$,

where $f$ is the correction factor with a value of $1.4845 \mathrm{ob}-$ tained from our previous study (Zhong and Jang, 2011) for the purpose of eliminating the absorbance caused by filter material scattering, $A$ is the filter surface area sampled $\left(7.85 \times 10^{-5} \mathrm{~m}^{2}\right.$ in this study), and $V$ is the volume $\left(\mathrm{m}^{3}\right)$ of air passing through the filter during a given sampling time. AbsoC is obtained from Eq. (1).

\subsection{Effect of photochemical aging on light absorption of OC}

Our chamber experimental data showed that light absorption of wood-burning OC was significantly modified due to photochemical aging. Figure $1 \mathrm{~b}$ shows the typical $\mathrm{MAC}_{\mathrm{OC}}$ of wood smoke exposed to sunlight using the outdoor chamber at different daytime hours. Overall, $\mathrm{MAC}_{\mathrm{OC}}$ increased with aging time in the morning. The total $\mathrm{MAC}_{\mathrm{OC}}$, which is estimated as the area under the $\mathrm{MAC}_{\mathrm{OC}}$ spectrum curve
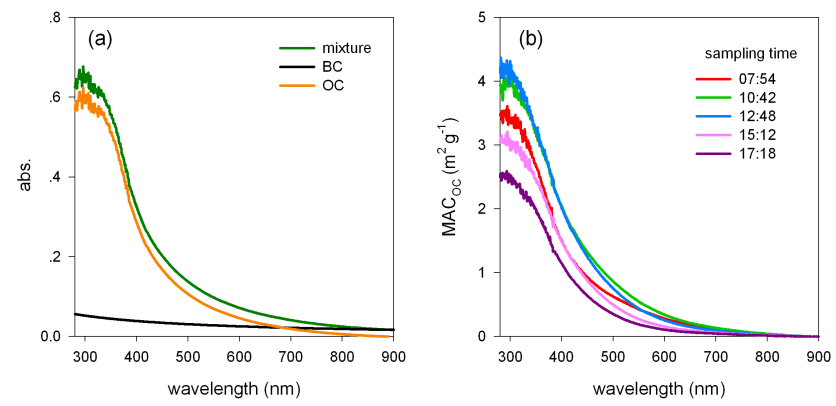

Fig. 1. (a) The decoupled absorbance spectrum of wood smoke OC obtained by subtracting the $\mathrm{BC}$ absorbance from the total absorbance of wood-burning particles. (b) The diurnal pattern of MAC $_{\mathrm{OC}}$ of wood smoke OC photochemically aged under natural sunlight (11 October 2012, medium $\mathrm{NO}_{\mathrm{x}}$ ) .

between 280 and $600 \mathrm{~nm}$, increased by $11-54 \%$ (26\% on average) except in data from the high-RH condition (west chamber on 24 October 2012). Saleh et al. (2013) explained that the increment in aged OC absorption is caused by the formation of SOA, which absorbs more than fresh POA in the short-wavelength visible and near-UV regions. Schauer et al. (2001) reported that about $34 \%$ of identified organic compounds in the gas phase and $41 \%$ of organic compounds identified in POA were phenols, syringols, and guaiacols. These phenols and methoxylated phenols in the gas or particle phase can rapidly react with atmospheric oxidants to form light-brown substances (Gelencser et al., 2003; Chang and Thompson, 2010; Ofner et al., 2011). Thus, the enhancement in light absorption would be caused by either oxidized POA or SOA produced via oxidation of primary phenolic compounds.

However, light absorption of OC at both UV and visible ranges gradually decreased in the afternoon. The total MAC $_{O C}$ decreased by $19-68 \%$ ( $41 \%$ on average) at the end of the experiment. A possible explanation for the decreases in $\mathrm{MAC}_{\mathrm{OC}}$ is bleaching of chromophores by sunlight. The previous study by Zhong and Jang (2011) reported the bleaching effect of light on light absorption of SOA. In wood smoke POA and SOA, there is an abundance of chromophores, such as conjugated aromatic rings and phenols, as well as nitroand hydroxyl groups. High-energy photons in sunlight can excite electrons in colored molecules through $\pi-\pi^{*}$ or $n-$ $\pi *$ transitions and disrupt the conjugated structure of chromophores, resulting in the gradual fading of wood smoke color. In order to prove that the color change of OC is mainly via photooxidation processes under the sunlight, an additional outdoor chamber experiment was conducted at night (27 September 2013). As shown in Fig. S2, no significant change appears in $\mathrm{MAC}_{\mathrm{OC}}$ within the error range. 

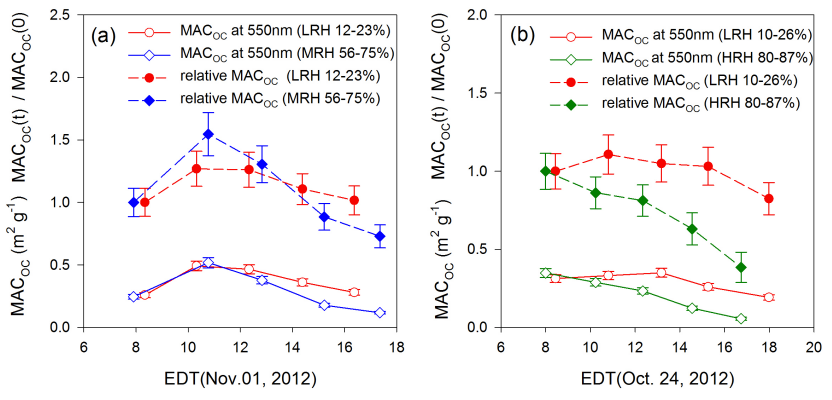

Fig. 2. Comparison of light absorption of wood OA photochemically oxidized at different conditions: (a) low RH vs. medium RH, and (b) low RH vs. high RH. The open symbols are for $\mathrm{MAC}_{\mathrm{OC}}$ at $550 \mathrm{~nm}$. The filled symbols are for the relative $\mathrm{MAC}_{\mathrm{OC}}$, which is expressed as the total $\mathrm{MAC}_{\mathrm{OC}}$ divided by the initial total $\mathrm{MAC}_{\mathrm{OC}}$. The uncertainties associated with OC mass absorption cross section in Eqs. (1)-(3) are estimated using propagation of errors from OC/EC analyzer, UV-visible spectrometer, and the correction factor $f$ (Eq. 5). Uncertainty of OC/EC analyzer was determined by dividing $0.5 \mu \mathrm{g} \mathrm{m}^{-3}$ (the absolute error) by the measured OC value. Uncertainty of the UV-visible spectrometer was determined by dividing 0.002 (the absolute error) by the measured absorbance. The standard error of $f$ is $8 \%$, which is estimated from the linear regression of calibration data (Zhong and Jang, 2011).

\subsection{Effect of RH on light absorption of OC}

In order to investigate the effect of humidity on $\mathrm{MAC}_{\mathrm{OC}}$, two sets of wet-dry dual chamber experiments were conducted: high RH (80-87\%) vs. low RH (10-26\%) on 24 October 2012, and medium RH (56-75\%) vs. low RH (12-23\%) on 1 November 2012. Figure 2 illustrates the time profile of the relative $\mathrm{MAC}_{\mathrm{OC}}$ and $\mathrm{MAC}_{\mathrm{OC}}$ at $550 \mathrm{~nm}$. The relative $\mathrm{MAC}_{\mathrm{OC}}$ was obtained by normalizing the total $\mathrm{MAC}_{\mathrm{OC}}$ at a certain time by the total $\mathrm{MAC}_{\mathrm{OC}}$ of fresh wood smoke. The fresh wood smoke particles were sampled after the injection of wood smoke in the early morning. As photooxidation progressed in the afternoon, the absorption decay at wet conditions became more rapid than the decay at dry conditions. For example, at the end of the experiment, the relative $\mathrm{MAC}_{\mathrm{OC}}$ as well as $\mathrm{MAC}_{\mathrm{OC}}$ at $550 \mathrm{~nm}$ at the low RH were higher by 43 and $45 \%$, respectively, compared to those at the high RH. Unlike $\mathrm{MAC}_{\mathrm{OC}}$ values in the medium or low RH conditions, no increase appeared for $\mathrm{MAC}_{\mathrm{OC}}$ values in the high- $\mathrm{RH}$ experiments. Elevated values of relative humidity can increase the water content of wood smoke particles (see Sect. 3.5.4 "Hygroscopic properties of wood-burning aerosol"). Anastasio et al. (1997) reported that illumination of aqueous-phase non-phenolic aromatic carbonyls in the presence of phenols can produce $\mathrm{H}_{2} \mathrm{O}_{2}$ and destroy phenols. Since both the aromatic carbonyls and phenols are major products from the combustion of wood (Rogge et al., 1998), this aqueous-phase photooxidation would produce a significant amount of $\mathrm{H}_{2} \mathrm{O}_{2}$. In wet aerosols, $\mathrm{H}_{2} \mathrm{O}_{2}$ can photodissociate to produce $\mathrm{OH}$
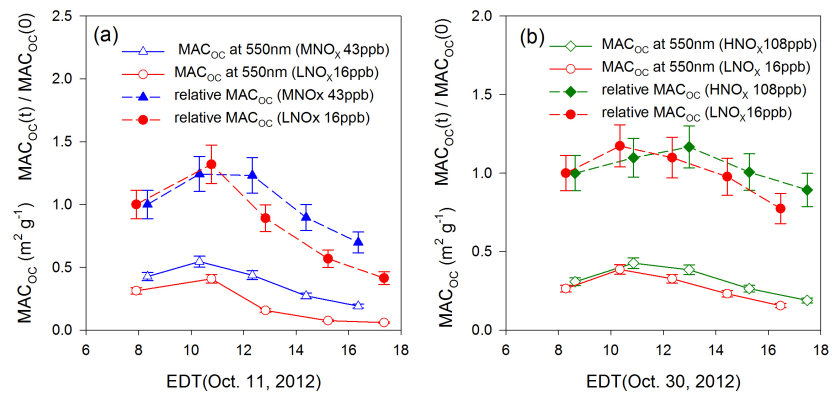

Fig. 3. Comparison of light absorption of wood OA photochemically oxidized at different conditions: (a) low $\mathrm{NO}_{\mathrm{x}}$ vs. medium $\mathrm{NO}_{\mathrm{x}}$, and (b) low $\mathrm{NO}_{\mathrm{x}}$ vs. high $\mathrm{NO}_{\mathrm{x}}$. The open symbols are for $\mathrm{MAC}_{\mathrm{OC}}$ at $550 \mathrm{~nm}$. The filled symbols are for the relative $\mathrm{MAC}_{\mathrm{OC}}$, which is expressed as the total $\mathrm{MAC}_{\mathrm{OC}}$ divided by initial total $\mathrm{MAC}_{\mathrm{OC}}$. The uncertainties associated with OC mass absorption cross section in Eqs. (1)-(3) are estimated using propagation of errors from OC/EC analyzer, UV-visible spectrometer, and the correction factor $f$ (Eq. 5). Uncertainty of OC/EC analyzer was determined by dividing $0.5 \mu \mathrm{g} \mathrm{m}^{-3}$ (the absolute error) by the measured OC value. Uncertainty of UV-visible spectrometer was determined by dividing 0.002 (the absolute error) by the measured absorbance. The standard error of $f$ is $8 \%$, which is estimated from the linear regression of calibration data (Zhong and Jang, 2011).

radicals (Zellner et al., 1990; Faust, 1994), which could decompose chromophores and lead to bleaching of wood OC.

\subsection{Effect of $\mathrm{NO}_{\mathrm{x}}$ on light absorption of $\mathrm{OC}$}

Controlled dual chamber experiments were also conducted to study the influence of $\mathrm{NO}_{\mathrm{x}}$ on $\mathrm{MAC}$ OC of wood aerosols: low $\mathrm{NO}_{\mathrm{x}}(16 \mathrm{ppb})$ vs. high $\mathrm{NO}_{\mathrm{x}}(108 \mathrm{ppb})$ on 30 October 2012 and low $\mathrm{NO}_{\mathrm{x}}(16 \mathrm{ppb})$ vs. medium $\mathrm{NO}_{\mathrm{x}}(43 \mathrm{ppb})$ on 11 October 2012. The low- $\mathrm{NO}_{\mathrm{x}}$ condition indicates the $\mathrm{NO}_{\mathrm{x}}$ concentration originating from wood burning under the smoldering condition. Both the medium- $\mathrm{NO}_{\mathrm{x}}$ and high- $\mathrm{NO}_{\mathrm{x}}$ conditions simulate the photooxidation of the wood smoke mixed with the air in urban areas. In the United States, the average urban $\mathrm{NO}_{\mathrm{x}}$ concentrations vary between 18 and $114 \mathrm{ppb}$ (Baugues, 1986). Figure 3 shows the time profiles of the relative MAC $\mathrm{OC}_{\mathrm{OC}}$ values and $\mathrm{MAC}_{\mathrm{OC}}$ at $550 \mathrm{~nm}$ under different $\mathrm{NO}_{\mathrm{x}}$ concentrations. In the presence of high $\mathrm{NO}_{\mathrm{x}}$, the $\mathrm{MAC}_{\mathrm{OC}}$ values are slightly higher than those at low $\mathrm{NO}_{\mathrm{x}}$ concentration. $\mathrm{NO}_{\mathrm{x}}$ is able to modify the reaction pathway for organic compounds in the gas phase. As discussed in Sect. 3.1 ("Light absorption of OC"), nitro-phenols (e.g., nitro-catechols) and nitro-compounds can be produced through the photooxidation of phenolic organic compounds and contribute SOA. Nitro-phenols have been suggested to be strong candidates to represent light-absorbing toluene SOA (Nakayama et al., 2010; Zhong et al., 2012; Zhang et al., 2013). At higher $\mathrm{NO}_{\mathrm{x}}$ levels, the concentration of these chromophoric nitro-phenols can be greater, decelerating the decay of $\mathrm{MAC}_{\mathrm{OC}}$ of wood smoke OC. 

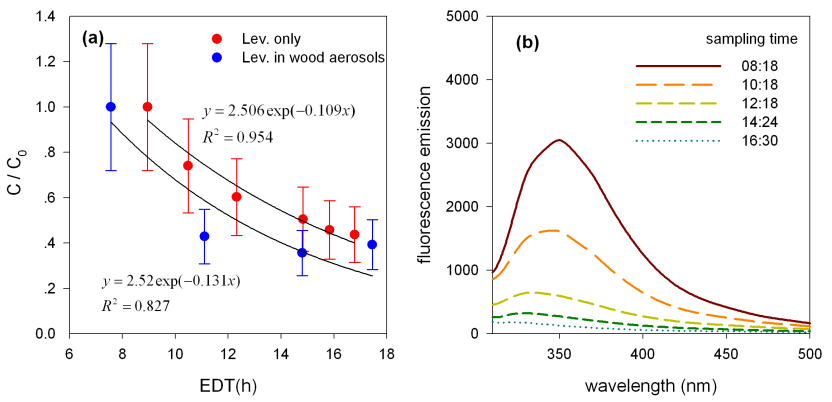

Fig. 4. (a) Time profile for the decay of pure levoglucosan $(27$ March 2013) and levoglucosan in wood smoke OA (21 November 2012). The concentrations of levoglucosan (C) were corrected for wall loss of particles and then normalized by the initial levoglucosan concentration $\left(C_{0}\right)$. The associated error with the measured concentration of levoglucosan by GC-MS is $\pm 20 \%$. (b) Fluorescence emission spectra of wood smoke particles collected at different times on 21 November 2012. The excitation wavelength was $280 \mathrm{~nm}$.

\subsection{Chemical and physical evolution of organic carbon aerosol}

To investigate how the chemical composition of wood smoke aerosol influences light absorption, the aerosol introduced into the chamber was characterized as photooxidation progressed. In this study, levoglucosan, a major constituent in wood smoke POA, was monitored by GC-ITMS. The intensity of fluorescence, which is mainly due to polycyclic aromatic hydrocarbons (PAHs), was measured for solventextracted aerosol samples. To study the alteration of the hygroscopic properties of wood smoke aerosol due to photooxidation, the aerosol water content was also measured by FTIR.

\subsubsection{Levoglucosan decay}

Levoglucosan is abundant in wood smoke aerosol, contributing 3-49\% of total wood smoke aerosol carbon (Mazzoleni et al., 2007). Figure 4a illustrates the rapid degradation of levoglucosan in both pure levoglucosan aerosol and wood smoke aerosol after wall-loss correction of aerosols. The experiment method for the pure levoglucosan experiment is provided in the supplementary material (document S1). The decay rate of the levoglucosan associated with wood smoke aerosol is similar to that of pure levoglucosan within the experimental error. The decrease of levoglucosan would be caused by wall loss of levoglucosan vapor and photochemical oxidation by $\mathrm{OH}$ radicals in the aerosol. According to Booth et al. (2011), the sub-cooled liquid vapor pressure of levoglucosan is $1.9 \times 10^{-4}$ pa at $298 \mathrm{~K}$; thus the wall loss of gas-phase levoglucosan is likely. In order to confirm the photochemical oxidation of levoglucosan, gas and aerosol samples were analyzed using GC-ITMS to identify the new products. Five products have been tentatively identified using the mass fragmentation spectra as shown in Figs. S3 and S4. The
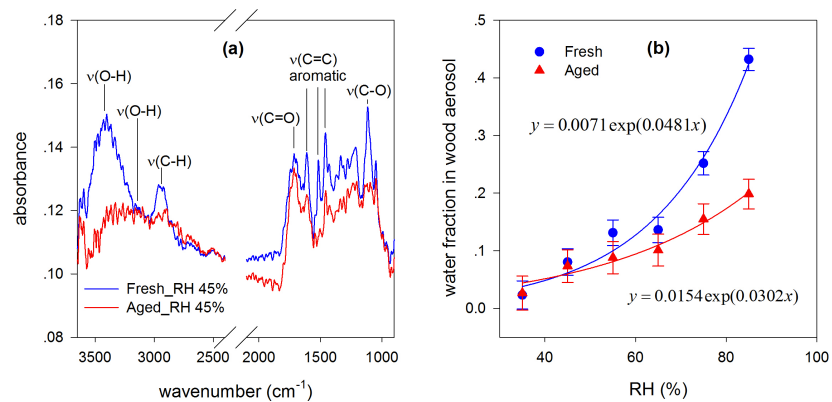

Fig. 5. (a) FTIR spectra of fresh and aged wood-burning particles sampled on 21 November 2012. The spectra were recorded at RH of $45 \%$. (b) The water content of fresh particles and aged particles as a function of RH. The water content was measured with decreasing $\mathrm{RH}$. The error associated with the water fraction in aerosol was estimated based on aerosol mass and FTIR absorbance at $1650 \mathrm{~cm}^{-1}$.

reaction pathways for the formation of the proposed products are illustrated in Fig. S5. However, the low amount of $\mathrm{O}_{3}$ formation suggests that oxidation of levoglucosan occurred mainly via aerosol-phase reaction.

\subsubsection{PAHs decay}

Unlike levoglucosan, the mass percentage of PAHs in wood smoke is less than $1 \%$ (Schauer et al., 2001). PAHs absorb UV light and emit fluorescence in the visible region. The photooxidation of PAHs can therefore be examined by measuring the fluorescence as a function of time. The fluorescence spectra of OC aerosol (Fig. 4b) show a rapid decrease in fluorescence emission when excited at $280 \mathrm{~nm}$. Similar to levoglucosan, such decline can be caused by both evaporation combined with increased temperature after the sun rises (Fig. S1) and photochemical oxidation of PAHs. PAHs can be transformed to oxy-PAHs via aerosol-phase oxidation (e.g., reaction with singlet oxygen produced by a photosensitizing process or reaction with $\mathrm{OH}$ radicals and free-radical reactions) (Jang and McDow, 1995). These oxy-PAHs generally have much lower fluorescence quantum yield compared to unoxidized PAHs.

\subsubsection{FTIR spectra of wood-burning aerosol}

Figure 5a compares the characteristic FTIR spectra of fresh and aged wood-burning particles at RH of $45 \%$. For the fresh particles, the $\mathrm{O}-\mathrm{H}$ stretching of alcohols is seen at $3500-3200 \mathrm{~cm}^{-1}$. The $\mathrm{C}=\mathrm{O}$ stretching of carbonyls (e.g., aldehydes, ketones, and carboxylic acids) occurs at 1800 $1680 \mathrm{~cm}^{-1}$, and the aromatic $\mathrm{C}=\mathrm{C}$ stretching bands appear at 1610,1517 , and $1458 \mathrm{~cm}^{-1}$. After photochemical aging of wood smoke aerosol for $5 \mathrm{~h}$, the absorbance for both the $\mathrm{O}-\mathrm{H}$ stretch of alcohols and the aromatic $\mathrm{C}=\mathrm{C}$ stretch significantly decreased. The FTIR spectrum of aged particles also showed the formation of carboxylic acids confirmed by the broad $\mathrm{O}-\mathrm{H}$ stretch at $3300-2500 \mathrm{~cm}^{-1}$ and the increased 


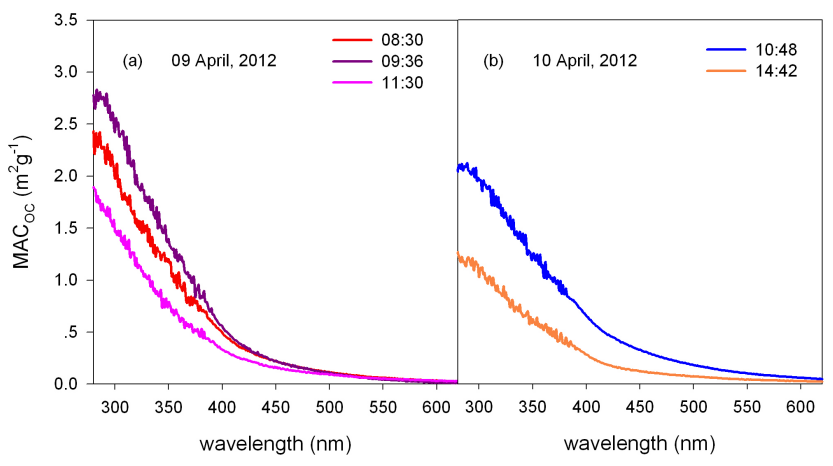

Fig. 6. Light absorption of ambient biomass-burning OA sampled during the County Line wildfire event on 9 April 2012 (a) and 10 April 2012 (b) at different sampling times.

absorbance at $\mathrm{C}=\mathrm{O}$ stretching frequency, suggesting oxidation of wood constituents.

\subsubsection{Hygroscopic properties of wood-burning aerosol}

To investigate the hygroscopicity of wood smoke particle, the water content of the particle was monitored using the FTIR equipped with a miniature flow chamber under varying RHs (Jang et al., 2010). The absorbance at $1650 \mathrm{~cm}^{-1}$, which is the characteristic frequency for $\mathrm{O}-\mathrm{H}$ bending of water, was used to estimate the water content in the aerosol. The peak at $1650 \mathrm{~cm}^{-1}$ was calibrated with the $\mathrm{NaCl}$ particle, which has a known water content obtained by an inorganic thermodynamic model at a given RH (e.g., AIM-III model, http: //www.aim.env.uea.ac.uk/aim/aim.php) (Clegg et al., 1998). As shown in Fig. 5b, the fresh particle was much more hygroscopic than the aged particle. The water content in fresh particles exponentially increased as a function of RH. No water was detected when the RH was lower than $25 \%$. In the morning, fresh wood smoke particles contain a high amount of the sugar compounds such as levoglucosan, which is very hydrophilic and easily absorbs water. As described in Sect. 3.5.1 ("Levoglucosan decay"), the amount of primary sugars rapidly decayed due to photooxidation. Although the carboxylic acid content increased with aging in aged wood aerosol (FTIR data in Fig. 5a), the aerosol became less hygroscopic. Martin et al. (2013) also reported the decline of hygroscopicity in photochemically aged wood smoke aerosol by measuring the growth factor of fresh and aged wood smoke particles using a tandem differential mobility analyzer.

\section{Conclusions and atmospheric implication}

The dynamic changes in light absorption of biomass-burning OC were investigated using the outdoor smog chamber under natural sunlight. The diurnal change in absorption of wood smoke aerosol is governed by two mechanisms: chro- mophore formation and sunlight bleaching. The colored products originating from photooxidation of phenolic types of semivolatile organic compounds (SVOCs) can increase wood smoke OA absorption in the morning, while sunlight fades the color of both POA and SOA in the afternoon. Higher concentrations of $\mathrm{NO}_{\mathrm{x}}$ help to prolong the wood smoke aerosol color (Fig. 3), but the high RH accelerates the degradation of aerosol color (Fig. 2). The decay of both PAHs and levoglucosan indicated dynamic changes in chemical composition of primary OC due to aging. The aged wood smoke OC became more oxidized but less hygroscopic, as shown by FITR spectra measurement.

The ambient data obtained during the County Line wildfire event on 9-10 April 2012 were analyzed using Eqs. (1)-(5) with a measured AAE of 0.74 for ambient BC. Figure 6 shows the light absorption of ambient biomass-burning OC after subtracting background OC. Compared to the $\mathrm{MAC}_{\mathrm{OC}}$ sampled at 08:30LT, the $\mathrm{MAC}_{\mathrm{OC}}$ sampled at 09:36 on 9 April increased by $18 \%$; however the $\mathrm{MAC}_{\mathrm{OC}}$ decreased by $28 \%$ at 11:30. The diurnal pattern in light absorption of the ambient biomass-burning OA is consistent with the result obtained in the outdoor chamber.

There is increased emphasis on research pertaining to the climate forcing of OC, including both experimental studies and model simulations. Considering the lifetime of aerosol (about six days), the results of both outdoor chamber studies (Fig. 1) and ambient field data (Fig. 6) suggest that biomassburning OC will absorb less light as photochemical reactions progress.

\section{Supplementary material related to this article is available online at http://www.atmos-chem-phys.net/14/ 1517/2014/acp-14-1517-2014-supplement.pdf.}

Acknowledgements. This work was supported by a grant from the National Science Foundation (ATM-0852747) and by a UF Alumni Scholarship. T. Boyer and S. Ishii are kindly acknowledged for the use of the fluorescence spectrometer.

Edited by: Y. Rudich

\section{References}

Adler, G., Flores, J. M., Abo Riziq, A., Borrmann, S., and Rudich, Y.: Chemical, physical, and optical evolution of biomass burning aerosols: a case study, Atmos. Chem. Phys., 11, 1491-1503, doi:10.5194/acp-11-1491-2011, 2011.

Alves, C. A., Vicente, A., Monteiro, C., Gonalves, C., Evtyugina, M., and Pio, C.: Emission of trace gases and organic components in smoke particles from a wildfire in a mixedevergreen forest in Portugal, Sci. Total Environ., 409, 14661475, doi:10.1016/j.scitotenv.2010.12.025, 2011. 
Anastasio, C., Faust, B. C., and Rao, C. J.: Aromatic Carbonyl Compounds as Aqueous-Phase Photochemical Sources of Hydrogen Peroxide in Acidic Sulfate Aerosols, Fogs, and Clouds. 1. Non-Phenolic Methoxybenzaldehydes and Methoxyacetophenones with Reductants (Phenols), Environ. Sci. Technol., 31, 218-232, doi:10.1021/es960359g, 1997.

Bahner, M. A., Weitz, K. A., and Zapata, A.: Use of Black Carbon and Organic Carbon Inventories for Projections and Mitigation Analysis, in: EPA Emissions Inventory Conference, Research Triangle Park, N.C, 2007.

Baugues, K.: Review of NMOC, $\mathrm{NO}_{\mathrm{x}}$ and $\mathrm{NMOC} / \mathrm{NO}_{\mathrm{x}}$ ratios measured in 1984 and 1985, Tech. Rep., Environmental Protection Agency, Research Triangle Park, NC, USA, 1986.

Bertschi, I., Yokelson, R. J., Ward, D. E., Babbitt, R. E., Susott, R. A., Goode, J. G., and Hao, W. M.: Trace gas and particle emissions from fires in large diameter and belowground biomass fuels, J. Geophys. Res.-Atmos., 108, 8472, doi:10.1029/2002JD002100, 2003.

Bond, T. and Bergstrom, R.: Light Absorption by Carbonaceous Particles: An Investigative Review, Aerosol Sci. Tech., 40, $27-$ 67, doi:10.1080/02786820500421521, 2006.

Bond, T. C., Doherty, S. J., Fahey, D. W., Forster, P. M., Berntsen, T., DeAngelo, B. J., Flanner, M. G., Ghan, S., Kärcher, B., Koch, D., Kinne, S., Kondo, Y., Quinn, P. K., Sarofim, M. C., Schultz, M. G., Schulz, M., Venkataraman, C., Zhang, H., Zhang, S., Bellouin, N., Guttikunda, S. K., Hopke, P. K., Jacobson, M. Z., Kaiser, J. W., Klimont, Z., Lohmann, U., Schwarz, J. P., Shindell, D., Storelvmo, T., Warren, S. G., and Zender, C. S.: Bounding the role of black carbon in the climate system: A scientific assessment, J. Geophys. Res.-Atmos., 118, 5380-5552, doi:10.1002/jgrd.50171, 2013.

Booth, A. M., Montague, W. J., Barley, M. H., Topping, D. O., McFiggans, G., Garforth, A., and Percival, C. J.: Solid state and subcooled liquid vapour pressures of cyclic aliphatic dicarboxylic acids, Atmos. Chem. Phys., 11, 655-665, doi:10.5194/acp-11655-2011, 2011.

Chang, J. L. and Thompson, J. E.: Characterization of colored products formed during irradiation of aqueous solutions containing $\mathrm{H}_{2} \mathrm{O}_{2}$ and phenolic compounds, Atmos. Environ., 44, 541-551, doi:10.1016/j.atmosenv.2009.10.042, 2010.

Chen, Y. and Bond, T. C.: Light absorption by organic carbon from wood combustion, Atmos. Chem. Phys., 10, 1773-1787, doi:10.5194/acp-10-1773-2010, 2010.

Clegg, S. L., Brimblecombe, P., and Wexler, A. S.: Thermodynamic Model of the System $\mathrm{H}^{+}-\mathrm{NH}_{4}^{+}-\mathrm{Na}^{+}-\mathrm{SO}_{4}^{2-}-\mathrm{NO}_{3}$ $-\mathrm{Cl}-\mathrm{H}_{2} \mathrm{O}$ at $298.15 \mathrm{~K}$, Phys. Chem. A, 102, 2155-2171, doi:10.1021/jp973043j, 1998.

Del Vecchio, R. and Blough, N. V.: On the Origin of the Optical Properties of Humic Substances, Environ. Sci. Technol., 38, 3885-3891, doi:10.1021/es049912h, 2004.

Faust, B. C.: Photochemistry of Clouds, Fogs, and Aerosols, Environ. Sci. Technol., 28, 216A-222A, doi:10.1021/es00054a001, 1994.

Forster, P., Ramaswamy, V., Artaxo, P., Berntsen, T., Betts, R., Fahey, D. W., Haywood, J., Lean, J., Lowe, D. C., Myhre, G., Nganga, J., Prinn, R., Raga, G., Schulz, M., and Van Dorland, R.: Changes in Atmospheric Constituents and in Radiative Forcing, chap. 2, p. 129, Cambridge University Press, Cambridge, United Kingdom and New York, NY, USA, 2007.
Gelencser, A., Hoffer, A., Kiss, G., Tombacz, E., Kurdi, R., and Bencze, L.: In-situ Formation of Light-Absorbing Organic Matter in Cloud Water, J. Atmos. Chem., 45, 25-33, 2003.

Grieshop, A. P., Donahue, N. M., and Robinson, A. L.: Laboratory investigation of photochemical oxidation of organic aerosol from wood fires 2: analysis of aerosol mass spectrometer data, Atmos. Chem. Phys., 9, 2227-2240, doi:10.5194/acp-9-2227-2009, 2009.

Gu, Y., Liou, K. N., Jiang, J. H., Su, H., and Liu, X.: Dust aerosol impact on North Africa climate: a GCM investigation of aerosolcloud-radiation interactions using A-Train satellite data, Atmos. Chem. Phys., 12, 1667-1679, doi:10.5194/acp-12-1667-2012, 2012.

Hallquist, M., Wenger, J. C., Baltensperger, U., Rudich, Y., Simpson, D., Claeys, M., Dommen, J., Donahue, N. M., George, C., Goldstein, A. H., Hamilton, J. F., Herrmann, H., Hoffmann, T., Iinuma, Y., Jang, M., Jenkin, M. E., Jimenez, J. L., Kiendler-Scharr, A., Maenhaut, W., McFiggans, G., Mentel, Th. F., Monod, A., Prévôt, A. S. H., Seinfeld, J. H., Surratt, J. D., Szmigielski, R., and Wildt, J.: The formation, properties and impact of secondary organic aerosol: current and emerging issues, Atmos. Chem. Phys., 9, 5155-5236, doi:10.5194/acp-9-51552009, 2009.

Hays, M. D., Fine, P. M., Geron, C. D., Kleeman, M. J., and Gullett, B. K.: Open burning of agricultural biomass: Physical and chemical properties of particle-phase emissions, Atmos. Environ., 39, 6747-6764, doi:10.1016/j.atmosenv.2005.07.072, 2005.

Hille, M. G. and Stephens, S. L.: Mixed conifer forest duff consumption during prescribed fires: tree crown impacts, Forest Sci., 51, 417-424, 2005.

Hoffer, A., Gelencsér, A., Guyon, P., Kiss, G., Schmid, O., Frank, G. P., Artaxo, P., and Andreae, M. O.: Optical properties of humic-like substances (HULIS) in biomass-burning aerosols, Atmos. Chem. Phys., 6, 3563-3570, doi:10.5194/acp-6-3563-2006, 2006.

Im, Y., Jang, M., and Beardsley, R. L.: Simulation of aromatic SOA formation using the lumping model integrated with explicit gas-phase kinetic mechanisms and aerosol-phase reactions, Atmos. Chem. Phys. Discuss., 13, 5843-5870, doi:10.5194/acpd13-5843-2013, 2013.

Jacobson, M. Z.: A physically-based treatment of elemental carbon optics: Implications for global direct forcing of aerosols, Geophys. Res. Lett., 27, 217-220, doi:10.1029/1999GL010968, 2000.

Jang, J., Jang, M., Mui, W., Delcomyn, C. A., Henley, M. V., and Hearn, J. D.: Formation of Active Chlorine Oxidants in Saline-Oxone Aerosol, Aerosol Sci. Tech., 44, 1018-1026, doi:10.1080/02786826.2010.507612, 2010.

Jang, M. and McDow, S. R.: Benz[a]anthracene photodegradation in the presence of known organic constituents of atmospheric aerosols, Environ. Sci. Technol., 29, 2654-2660, doi:10.1021/es00010a030, 1995.

Jimenez, J. L., Canagaratna, M. R., Donahue, N. M., Prevot, A. S. H., Zhang, Q., Kroll, J. H., DeCarlo, P. F., Allan, J. D., Coe, H., Ng, N. L., Aiken, A. C., Docherty, K. S., Ulbrich, I. M., Grieshop, A. P., Robinson, A. L., Duplissy, J., Smith, J. D., Wilson, K. R., Lanz, V. A., Hueglin, C., Sun, Y. L., Tian, J., Laaksonen, A., Raatikainen, T., Rautiainen, J., Vaattovaara, P., Ehn, M., Kulmala, M., Tomlinson, J. M., Collins, D. R., Cubison, 
M. J., E., Dunlea, J., Huffman, J. A., Onasch, T. B., Alfarra, M. R., Williams, P. I., Bower, K., Kondo, Y., Schneider, J., Drewnick, F., Borrmann, S., Weimer, S., Demerjian, K., Salcedo, D., Cottrell, L., Griffin, R., Takami, A., Miyoshi, T., Hatakeyama, S., Shimono, A., Sun, J. Y., Zhang, Y. M., Dzepina, K., Kimmel, J. R., Sueper, D., Jayne, J. T., Herndon, S. C., Trimborn, A. M., Williams, L. R., Wood, E. C., Middlebrook, A. M., Kolb, C. E., Baltensperger, U., and Worsnop, D. R.: Evolution of Organic Aerosols in the Atmosphere, Science, 326, 1525-1529, doi:10.1126/science.1180353, 2009.

Kirchstetter, T. W. and Thatcher, T. L.: Contribution of organic carbon to wood smoke particulate matter absorption of solar radiation, Atmos. Chem. Phys., 12, 6067-6072, doi:10.5194/acp-126067-2012, 2012.

Kirchstetter, T. W., Novakov, T., and Hobbs, P. V.: Evidence that the spectral dependence of light absorption by aerosols is affected by organic carbon, J. Geophys. Res.-Atmos., 109, D21208, doi:10.1029/2004JD004999, 2004.

Lack, D. A., Langridge, J. M., Bahreini, R., Cappa, C. D., Middlebrook, A. M., and Schwarz, J. P.: Brown carbon and internal mixing in biomass burning particles, P. Natl. Acad. Sci., 109, 14802-14807, doi:10.1073/pnas.1206575109, 2012.

Martin, M., Tritscher, T., Jurányi, Z., Heringa, M. F., Sierau, B., Weingartner, E., Chirico, R., Gysel, M., Prévôt, A. S., Baltensperger, U., and Lohmann, U.: Hygroscopic properties of fresh and aged wood burning particles, J. Aerosol Sci., 56, 1529, doi:10.1016/j.jaerosci.2012.08.006, 2013.

Mazzoleni, L. R., Zielinska, B., and Moosmüller, H.: Emissions of Levoglucosan, Methoxy Phenols, and Organic Acids from Prescribed Burns, Laboratory Combustion of Wildland Fuels, and Residential Wood Combustion, Environ. Sci. Technol., 41, 21152122, doi:10.1021/es061702c, 2007.

Nakayama, T., Matsumi, Y., Sato, K., Imamura, T., Yamazaki, A., and Uchiyama, A.: Laboratory studies on optical properties of secondary organic aerosols generated during the photooxidation of toluene and the ozonolysis of $\alpha$-pinene, J. Geophys. Res.Atmos., 115, D24204, doi:10.1029/2010JD014387, 2010.

Ofner, J., Krüger, H.-U., Grothe, H., Schmitt-Kopplin, P., Whitmore, K., and Zetzsch, C.: Physico-chemical characterization of SOA derived from catechol and guaiacol - a model substance for the aromatic fraction of atmospheric HULIS, Atmos. Chem. Phys., 11, 1-15, doi:10.5194/acp-11-1-2011, 2011.

Quinn, P. K., Bates, T. S., Baum, E., Doubleday, N., Fiore, A. M., Flanner, M., Fridlind, A., Garrett, T. J., Koch, D., Menon, S., Shindell, D., Stohl, A., and Warren, S. G.: Short-lived pollutants in the Arctic: their climate impact and possible mitigation strategies, Atmos. Chem. Phys., 8, 1723-1735, doi:10.5194/acp8-1723-2008, 2008.
Reid, J. S., Koppmann, R., Eck, T. F., and Eleuterio, D. P.: A review of biomass burning emissions part II: intensive physical properties of biomass burning particles, Atmos. Chem. Phys., 5, 799825, doi:10.5194/acp-5-799-2005, 2005.

Rogge, W. F., Hildemann, L. M., Mazurek, M. A., and Cass, G. R. A.: Sources of Fine Organic Aerosol. 9. Pine, Oak, and Synthetic Log Combustion in Residential Fireplaces, Environ. Sci. Technol., 32, 13-22, doi:10.1021/es960930b, 1998.

Rudich, Y., Donahue, N. M., and Mentel, T. F.: Aging of Organic Aerosol: Bridging the Gap Between Laboratory and Field Studies, Annu. Rev. Phys. Chem., 58, 321-352, doi:10.1146/annurev.physchem.58.032806.104432, 2007.

Saleh, R., Hennigan, C. J., McMeeking, G. R., Chuang, W. K., Robinson, E. S., Coe, H., Donahue, N. M., and Robinson, A. L.: Absorptivity of brown carbon in fresh and photo-chemically aged biomass-burning emissions, Atmos. Chem. Phys., 13, 76837693, doi:10.5194/acp-13-7683-2013, 2013.

Schauer, J. J., Kleeman, M. J., Cass, G. R., and Simoneit, B. R. T.: Measurement of Emissions from Air Pollution Sources. 3. C1C29 Organic Compounds from Fireplace Combustion of Wood, Environ. Sci. Technol., 35, 1716-1728, doi:10.1021/es001331e, 2001.

Schnaiter, M., Schmid, O., Petzold, A., Fritzsche, L., Klein, K. F., Andreae, M. O., Helas, G., Thielmann, A., Gimmler, M., Möhler, O., Linke, C., and Schurath, U.: Measurement of Wavelength-Resolved Light Absorption by Aerosols Utilizing a UV-VIS Extinction Cell, Aerosol Sci. Technol., 39, 249-260, doi:10.1080/027868290925958, 2005.

Zellner, R., Exner, M., and Herrmann, H.: Absolute OH quantum yields in the laser photolysis of nitrate, nitrite and dissolved $\mathrm{H}_{2} \mathrm{O}_{2}$ at 308 and $351 \mathrm{~nm}$ in the temperature range $278-353 \mathrm{~K}$, J. Atmos. Chem., 10, 411-425, 1990.

Zhang, X., Lin, Y.-H., Surratt, J. D., and Weber, R. J.: Sources, Composition and Absorption Ångström Exponent of Lightabsorbing Organic Components in Aerosol Extracts from the Los Angeles Basin, Environ. Sci. Technol., 47, 3685-3693, doi:10.1021/es305047b, 2013.

Zhong, M. and Jang, M.: Light absorption coefficient measurement of SOA using a UV-visible spectrometer connected with an integrating sphere, Atmos. Environ., 45, 4263-4271, doi:10.1016/j.atmosenv.2011.04.082, 2011.

Zhong, M., Jang, M., Oliferenko, A., Pillai, G., and Katritzky, A.: The SOA formation model combined with semiempirical quantum chemistry for predicting UV-Vis absorption of secondary organic aerosols, Phys. Chem. Chem. Phys., 14, 9058, doi:10.1039/c2cp23906j, 2012. 